\title{
Exploring the use of and perceptions about honey as complementary and alternative medicine among the general public in the state of Selangor, Malaysia
}

\author{
Mohd Shahezwan Abd Wahab ${ }^{1}$, Noordin Othman ${ }^{2 *}$, Noor Hazwani Izzati Othman ${ }^{1}$, Amirah Adhwani Jamari ${ }^{1}$, \\ Aida Azlina $\mathrm{Ali}^{3}$ \\ ${ }^{1}$ Department of Pharmacy Practice, Faculty of Pharmacy, Universiti Teknologi MARA Selangor, 42300 Puncak Alam, Malaysia. \\ ${ }^{2}$ Department of Clinical and Hospital Pharmacy, College of Pharmacy, Taibah University, PO Box 344, Al-Madinah Al-Munawwarah, Saudi Arabia. \\ ${ }^{3}$ Department of Pharmacy Practice, Faculty of Pharmacy, Universiti Teknologi MARA Selangor, 42300 Puncak Alam, Malaysia.
}

\begin{tabular}{l}
\hline ARTICLE INFO \\
\hline Article history: \\
Received on: $13 / 07 / 2017$ \\
Accepted on: 15/10/2017 \\
Available online: $30 / 12 / 2017$ \\
\hline Key words: \\
Complementary and \\
alternative medicine; honey; \\
Malaysia; perceptions, \\
survey.
\end{tabular}

\begin{abstract}
Objective: Honey has been used as a biologically-based complementary and alternative medicine (CAM) since ancient times. The present study aimed to explore the use of and the perceptions about honey as a CAM among the general public in Selangor.

Method: A cross-sectional study using a self-completed questionnaire was employed. Participants were recruited using convenience sampling method from three towns in the state of Selangor.

Results: $56 \%(168 / 300)$ of respondents used honey as CAM. Most users used honey as a dietary supplement for well-being $(71.4 \%, 120 / 168)$, or to treat coughs $(57.1 \%, 96 / 168)$, and sore throats $(53 \%, 89 / 168)$. A small percentage of users $(13.1 \%, 22 / 168)$ used honey to treat asthma. The respondents generally showed favourable perceptions about honey as CAM as more than $60 \%$ of them rated strongly agree and agree for each of the perception item in the survey. The users obtained their supply of honey from supermarkets $(42.3 \%, 71 / 168)$, grocery stores $(32.7 \%, 55 / 168)$, and friends/family $(31 \%, 52 / 168)$. In addition, most users sought information about honey from friends/family $(63.1 \%, 106 / 168)$, the Internet $(60.7 \%, 102 / 168)$ and advertisements $(39.3 \%$, $66 / 168)$.

Conclusion: The respondents generally had favourable perceptions about honey as CAM. Future work should aim to produce more scientific evidences of the benefits and safety of honey. The use of honey supplies from unreliable sources as CAM and unreliable sources of information as well as potential self-medication with honey for serious diseases should raise concerns.
\end{abstract}

\section{INTRODUCTION}

The use of the complementary and alternative medicine (CAM) is common among the general public (Ventola, 2010). The two main CAM categories are the biologically-based therapies (e.g., herbs, vitamins, and minerals) and the mind-body

\footnotetext{
* Corresponding Author

Noordin Othman, Department of Clinical and Hospital Pharmacy, College of Pharmacy, Taibah University, PO Box 344, Al-Madinah AlMunawwarah, 30001 Saudi Arabia. Tel.: +966559234544;

Fax:+96648461172.E-mail:noordin_uia @yahoo.com
}

practices (e.g., massage, acupuncture, and meditation). Among the CAM modalities, the biologically-based therapies have been reported as the most commonly used in many previous studies (Siti et al., 2009; Clarke et al., 2015; Barnes et al., 2007). In a nationwide survey in Malaysia, $69.4 \%$ (4821/6947) of the respondents had used CAM at least once in their lifetime and 55.6 $\%(3863 / 6947)$ of them had used CAM within the previous 12 months of the survey (Siti et al., 2009). In the survey, the use of the biologically-based therapies were found to be the most common with $88.9 \%$ and $87.3 \%$ of the surveyed CAM users had used the modalities to overcome their health problems and maintain their health, respectively (Siti et al., 2009). 
Honey has been used as a biologically-based CAM since ancient times (Eteraf-Oskouei and Najafi, 2013). In Malaysia, people have often used honey in combination with other herbs to treat diseases or to maintain their health (Siti et al., 2009). The use of honey as CAM has also been reported in many other countries such as Argentina (Kujawska et al., 2012), India (Savithramma et al., 2007), Korea (Lee et al., 2004) and the United States of America (U.S.A.) (Burge and Albright, 2002). In a survey carried out in Romania, $20.5 \%$ (45/220) respondents stated that they would consume honey as medicine.

The 2003 survey has identified the medical benefit of honey as an important motivation factor for the Romanian people to use honey (Arvanitoyannis and Krystallis, 2006). In a more recent Romanian survey carried out in 2012, $98 \%(1421 / 1449)$ of respondents reported that they had consumed honey and $88 \%$ (1275/1449) of all respondents agreed that honey would be good for health (Pocol and Bolboacă, 2013). In another survey in Saudi Arabia, $87.3 \%$ (289/331) of respondents claimed that they had used honey because of its medicinal properties (Ismaiel et al., 2014).

Honey mostly consists of fructose and glucose. However, it also contains a wide range of substances such as phytochemicals, flavonoids, enzymes, vitamins, minerals and other compounds (Ajibola, 2015). The constituents of honey work synergistically to produce its medicinal effects (Eteraf-Oskouei and Najafi, 2013; Ajibola, 2015). Over the past decades, numerous laboratory and clinical studies have shown the efficacy of honey especially in terms of its antibacterial properties, and in wound management (Eteraf-Oskouei and Najafi, 2013; Ajibola, 2015). In addition, the benefits of using honey in treating ophthalmic and dental diseases, and common ailments such as coughs, have also been reported (Salehi et al., 2014; Atwa et al., 2014; Paul et al., 2007). Moreover, animal model studies have suggested that honey may be beneficial in the treatment of metabolic, cardiovascular, and neoplastic diseases (Eteraf-Oskouei and Najafi, 2013; Hussein et al., 2012; Bardy et al., 2008; Abdulrhman et al., 2013). The usefulness of honey and its well-documented antioxidant and antiinflammatory properties make it attractive and viable to be developed as a treatment modality for various diseases, and for the maintenance of health (Ajibola, 2015; Bhatti et al., 2016). Although there are many studies which are in favor of the usefulness of honey in the treatment of various diseases, information about its use and perceptions of the general public about honey as CAM is still lacking. Previous studies which sought public opinions about honey were mainly market surveys or consumer behavior studies that focused on honey as food. This present study aimed to explore the use of honey and the perceptions of the public in the state of Selangor, Malaysia about honey as CAM.

The findings from this study may be used to assist the healthcare professionals in gaining a better understanding of the use of honey as CAM and may draw the attention of researchers for further investigations to produce more scientific evidences of the benefits and safety of honey.

\section{Methods}

This study was a cross-sectional survey which explored the use of and the perceptions of the public about honey as CAM. A questionnaire was developed based on relevant literature with some modifications (Pocol and Bolboacă, 2013; Wahab et al., 2014; Mitha et al., 2013; Hassali et al., 2012a). The questionnaire was constructed in the English language, translated into Malay and then back-translated into English to ensure its accuracy and validity. The final questionnaire contained survey items in both languages. To assess face and content validity, the questionnaire was reviewed by professors in pharmacy and researchers whose studies were related to honey. The questionnaire was then piloted among 50 adults who were sampled using convenience sampling technique to assess its readability, clarity and comprehensibility. However, results from the pilot survey were not included in the final data analysis. In the main study, honey would be considered as CAM if it was used to treat diseases, or to promote health and/or general well-being in the past three months. The questionnaire consisted of two sections: (1) respondents' demographic details and their patterns of honey use; and (2) perceptions about honey as CAM. In the second section of the questionnaire, respondents were asked to indicate their agreement using a 5-point Likert type scale ranging from $1=$ strongly disagree to 5=strongly agree. The study received ethical approval from the ethical committee of the Faculty of Pharmacy of Universiti Teknologi MARA (UiTM).

The respondents of the survey were members of the general public selected from three towns in Selangor, a west coast state of Peninsular Malaysia. The three selected towns, namely, Shah Alam, Puncak Alam, and Sabak Bernam, were chosen due to logistic reasons. In the present study, 100 respondents were recruited from each town using non-proportional quota sampling method.

In each town, one main business area was identified and two researchers approached potential respondents to be recruited as participants in the study. Selection of the respondents was performed in a non-probability manner. Each individual who agreed to participate in the survey was assured of confidentiality and anonymity. The survey was self-completed by the respondents. The completion of the questionnaire indicated consent for their participation in the study. All data were analyzed using SPSS statistical software (version 23). For the purpose of analysis, the Likert-type scale responses of "strongly agree and agree" and "strongly disagree and disagree" were grouped together. Data analysis utilized the chi-squared or Fisher's exact tests for categorical variables and the independent t-test for continuous variables. A $P$ value of $<0.05$ would be considered significant.

\section{RESULTS}

Table 1 shows the demographic characteristics of the respondents. Out of 300 respondents who completed the questionnaires, $56 \%$ (168/300) indicated that they had used honey as CAM in the past three months. 
Table 1: Characteristics of study respondents.

\begin{tabular}{|c|c|c|c|c|}
\hline \multirow[t]{2}{*}{ Demographic characteristics } & Users $^{a}(n=168)$ & Non-users ${ }^{\mathrm{b}}(\mathrm{n}=132)$ & \multirow[t]{2}{*}{$P$ value } & \multirow{2}{*}{$\begin{array}{c}\text { Total } \\
(\mathbf{n}=\mathbf{3 0 0})\end{array}$} \\
\hline & \multicolumn{2}{|c|}{ Number (percentage) } & & \\
\hline Township & & & & \\
\hline Shah Alam & $57(33.9)$ & $43(32.6)$ & $0.08^{\mathrm{c}}$ & $100(33.3)$ \\
\hline Puncak Alam & $55(32.7)$ & $45(34.1)$ & & $100(33.3)$ \\
\hline Sabak Bernam & $56(33.3)$ & $44(33.3)$ & & $100(33.3)$ \\
\hline \multicolumn{5}{|l|}{ Gender } \\
\hline Male & 63 (37.5) & $57(43.2)$ & $0.32^{\mathrm{c}}$ & $120(40)$ \\
\hline Female & $105(62.5)$ & $75(56.8)$ & & $180(60)$ \\
\hline \multicolumn{5}{|l|}{ Age } \\
\hline Mean (SD) & $30.98(9.15)$ & $30.37(10.9)$ & $0.60^{\mathrm{d}}$ & $30.7(9.97)$ \\
\hline \multicolumn{5}{|l|}{ Age group } \\
\hline 30 and below & $96(57.1)$ & $80(60.6)$ & $0.55^{\mathrm{c}}$ & $176(58.7)$ \\
\hline 31 and above & $72(42.9)$ & $52(39.4)$ & & $124(41.3)$ \\
\hline \multicolumn{5}{|l|}{ Race } \\
\hline Malay & $144(85.7)$ & $91(68.9)$ & $<0.001^{\mathrm{c}}$ & $235(78.3)$ \\
\hline Non-Malay & $24(14.3)$ & $41(31.1)$ & & $65(21.7)$ \\
\hline \multicolumn{5}{|l|}{ Education level } \\
\hline University level & $126(75)$ & $96(72.7)$ & $0.66^{\mathrm{c}}$ & $222(74)$ \\
\hline Lower than university level & $42(25)$ & $36(27.3)$ & & $78(26)$ \\
\hline \multicolumn{5}{|l|}{ Monthly income $^{\mathrm{e}}$} \\
\hline RM 2000 and lower & $82(48.8)$ & $89(67.4)$ & $0.001^{\mathrm{c}}$ & $171(57)$ \\
\hline More than RM 2000 & $86(51.2)$ & $43(32.6)$ & & $129(43)$ \\
\hline
\end{tabular}

${ }^{\text {a }}$ Reported to use honey to treat diseases, or to promote health and/or general well-being in the past three months.

${ }^{b}$ Never use honey to treat diseases, or to promote health and/or general well-being in the past three months.

${ }^{\mathrm{c}}$ Chi-squared used.

${ }^{\mathrm{d}}$ Independent t-test used.

${ }^{\mathrm{e}} \mathrm{RM} 1$ is approximately USD 0.25 .

There was no significant difference in the use of honey as CAM among respondents from the three towns. Approximately 60 $\%(105 / 168)$ of the users were female. Most users $(57.1 \%$, $96 / 168)$ were 30 years and younger. The majority of the respondents were Malays $(78.3 \%, 235 / 300)$. Compared to the non-users of honey, the users were significantly more likely to comprise of respondents who identified themselves as Malays (users: $85.7 \%$ [144/168] vs. non-users: $68.9 \%$ [91/132]; $P<0.01$ ). In addition, the users of honey were significantly more likely to earn more than RM 2000 monthly compared to the non-users (users: $51.2 \%$ [86/168] vs. $32.6 \%$ [43/132]; $P<0.01$ ). Table 2 shows the patterns of use of honey among the users. The most common type of honey used was Tualang $(45.8 \%, 77 / 168)$. The majority of respondents used honey as a dietary supplement for well-being $(71.4 \%, 120 / 168)$. Many users claimed that they used honey to treat common ailments such as coughs $(57.1 \%, 96 / 168)$, and sore throats $(53 \%, 89 / 168)$. A small percentage of users (13.1 $\%, 22 / 168)$ used honey to treat asthma. The users obtained their honey supplies from the supermarkets $(42.3 \%, 71 / 168)$, grocery stores $(32.7 \%, 55 / 168)$, and from friends/family $(31 \%, 52 / 168)$. In addition, most users $(79.2 \%, 133 / 168)$ were willing to spend about RM 20 and higher for honey. Users sought information about honey from friends/family $(63.1 \%, 106 / 168)$, the Internet $(60.7 \%$, 102/168), advertisements $(39.3 \%, 66 / 168)$ and the newspaper $(37.5 \%, 63 / 168)$. In general, the respondents showed favourable perceptions about honey as CAM as more than $60 \%$ of them rated strongly agree and agree for each of the survey statement (Table 3 ). The majority of both the honey users and non-users strongly agreed and agreed that there was a sufficient evidence supports the benefits of honey as a complementary medicine (users: $66.1 \%$ [111/168] vs. $68.2 \%$ [90/132]; $P=0.85$ ) and that the use of honey as food supplement for general health should be promoted (users: $86.9 \%$ [146/168] vs. $80.3 \%$ [106/132]; $P=0.21)$. We found no significant difference in the perceptions of the users and non-users for the two survey statement.

Table 2: Pattern of honey use by users ${ }^{\mathrm{a}}(\mathrm{n}=168)$.

\begin{tabular}{lc}
\hline Pattern of honey use $^{\text {bype of honey used }}{ }^{\mathrm{b}}$ & $\mathbf{n}(\boldsymbol{\%})$ \\
Tualang $^{\text {Acacia }}$ & $77(45.8)$ \\
Kelulut & $20(11.9)$ \\
Nenas & $15(8.9)$ \\
Manuka & $11(6.5)$ \\
Gelam & $7(4.2)$ \\
Others & $6(3.6)$ \\
Unsure of the type & $23(13.7)$ \\
Used honey as dietary supplement for general well-being & $64(38.1)$ \\
\hline Used honey for treatment of diseases $^{\mathrm{b}}$ & $120(71.4)$ \\
Coughs & \\
Sore throat & $96(57.1)$ \\
Wound & $89(53)$ \\
Asthma & $28(16.7)$ \\
Animal stings & $22(13.1)$ \\
Skin diseases & $21(12.5)$ \\
Stomach ache & $21(12.5)$ \\
Ulcers & $9(5.4)$ \\
Others & $6(3.6)$ \\
Very frequent & $25(14.9)$ \\
Frequently & \\
Sometimes & $19(11.3)$ \\
Occasionally & $33(19.6)$ \\
Rarely & $65(38.7)$ \\
\hline Frequency of using honey & $18(10.7)$ \\
\hline
\end{tabular}




\begin{tabular}{lc}
\hline Source of obtainment of honey & \\
Supermarkets & $71(42.3)$ \\
Grocery stores & $55(32.7)$ \\
Friends and/or family & $52(31)$ \\
Health / organic stores & $35(20.8)$ \\
Pharmacies & $34(20.2)$ \\
Traditional medicine outlets & $26(15.5)$ \\
Night markets & $21(12.5)$ \\
Beekeepers & $20(11.9)$ \\
Online & $12(7.1)$ \\
Other sources & $18(10.7)$ \\
\hline Spending on honey ${ }^{\mathrm{b}}$ & \\
<RM 20 & $35(20.8)$ \\
RM 20 - RM 40 & $52(30.9)$ \\
RM 41 - RM 60 & $51(30.4)$ \\
$>$ RM 60 & $30(17.9)$ \\
\hline Friends and/or family & \\
Internet & $106(63.1)$ \\
Advertisements & $102(60.7)$ \\
Newspapers & $66(39.3)$ \\
Mass media (e.g. radio, television, etc.) & $63(37.5)$ \\
Books & $60(35.7)$ \\
Scientific articles & $50(29.8)$ \\
Health professionals & $33(19.6)$ \\
Others & $29(17.3)$ \\
\hline Source of information about hone & $12(7.1)$ \\
\hline${ }^{\mathrm{b}}$ RM 1 is approximately USD 0.25. & \\
\hline
\end{tabular}

In addition, although not using honey as CAM for the past 3 months of the survey, the majority of the non-users $(65.2 \%$, 86/132) rated strongly agree and agree that they would rather use honey to treat common ailments such as coughs and sore throats than using modern medicines. The honey users were significantly more likely to strongly agree and agree with the other 6 survey statements compared to the non-users. It was also observed that a significantly higher proportion of male respondents strongly agreed that there was sufficient evidence that supports the use of honey as CAM compared to the female respondents (male: $75 \%$ [90/120] vs. female: $61.7 \%$ [111/180]; $P=0.04$ ). The female respondents however were significantly more likely to strongly agree and agree that honey can stimulate body natural therapeutic power compared to their male counterpart (male: 55.8 $\%$ [67/120] vs. female: $64.4 \%$ [116/180]; $P<0.01)$. In regards to age, although the younger respondent group (30 years and below) were significantly more likely to strongly agree and agree that there is a need to disseminate information about honey to the public (younger: $84.7 \%$ [149/176] vs. older: $74.2 \%$ [92/124]; $P<$ 0.01 ), significantly higher proportions of respondents from the older group (31 years and above) strongly agree and agree that honey can stimulate body natural power (younger: $56.8 \%$, [100/176] vs. older: $66.9 \%$ [83/124]; $P=0.04)$, and that honey is easy to be used (younger: $78.4 \%$ [138/176] vs. older: $82.3 \%$ [102/124]; $P=0.01)$. Compared to their younger counterpart the respondents in the older group were also significantly more likely to strongly agree and agree that they would rather use honey as CAM to treat common ailments than using modern medicines (younger: 63.1\% [111/176] vs. older: $73.4 \%$ [91/124]; $P=0.03$ ). Overall, the Malay respondents appeared to be more favorable towards honey as CAM compared to the non-Malays. Significantly higher proportion of the Malay respondents rated strongly agree and agree to 7 out of 9 survey statements. Our findings also showed that those who had university education were more likely to strongly agree and agree that they would not mind to spend money on honey as CAM (university level: $64 \%$ [142/222] vs. lower than university level: $57.7 \%$ [45/78]; $P<0.01$ ). Although we found that those who earn more than RM 2000 and above monthly were more likely to use honey as CAM in the past 3 months of the survey compared those who earn less than RM 2000 a month, the higher earner group showed no significant difference in their perceptions about honey as CAM when compared to those in the lower earner group.

Table 3: Perceptions of respondents towards honey as CAM.

\begin{tabular}{|c|c|c|c|c|c|c|c|c|c|}
\hline \multirow[b]{2}{*}{ Statement } & \multicolumn{3}{|c|}{ Frequency $(\%)$ of responses } & \multicolumn{6}{|l|}{$P$ value } \\
\hline & $\begin{array}{l}\text { Strongly } \\
\text { Agree and } \\
\text { Agree }\end{array}$ & Neutral & $\begin{array}{l}\text { Disagree } \\
\text { and } \\
\text { Strongly } \\
\text { Disagree } \\
\end{array}$ & $\begin{array}{l}\text { Users / } \\
\text { Non- } \\
\text { users }\end{array}$ & Gender & Age & Ethnicity & $\begin{array}{l}\text { Education } \\
\text { level }\end{array}$ & Income \\
\hline $\begin{array}{l}\text { Sufficient evidence supports the benefits of honey } \\
\text { as a complementary medicine }\end{array}$ & $201(67)$ & $88(29.3)$ & $11(3.7)$ & 0.85 & 0.04 & 0.01 & 0.02 & 0.11 & 0.24 \\
\hline $\begin{array}{l}\text { The use of honey as food supplement for general } \\
\text { health should be promoted }\end{array}$ & $252(84)$ & $39(13)$ & $9(3)$ & 0.21 & 0.95 & 0.42 & 0.07 & 0.92 & 0.10 \\
\hline $\begin{array}{l}\text { More information should be provided to the public } \\
\text { regarding the health benefits of honey }\end{array}$ & $241(80.3)$ & $54(18)$ & $5(1.7)$ & $<0.01^{*}$ & $0.13 *$ & $<0.01 *$ & $<0.01^{*}$ & $0.11^{*}$ & $0.14^{*}$ \\
\hline $\begin{array}{l}\text { I believe that honey can stimulate body natural } \\
\text { therapeutic power }\end{array}$ & $183(61)$ & $76(25.3)$ & $41(13.7)$ & $<0.01$ & $<0.01$ & 0.04 & 0.02 & 0.76 & 0.62 \\
\hline $\begin{array}{l}\text { I would rather use honey to treat common } \\
\text { ailments such as coughs and sore throats than } \\
\text { using modern medicines }\end{array}$ & $202(67.3)$ & $78(26)$ & $20(6.7)$ & 0.18 & 0.64 & 0.03 & 0.26 & 0.73 & 0.90 \\
\hline $\begin{array}{l}\text { I would recommend honey to others as an } \\
\text { alternative to modern medicine in treating } \\
\text { common ailments }\end{array}$ & $211(70.3)$ & $69(23)$ & $20(6.7)$ & $<0.01$ & 0.33 & 0.61 & 0.01 & 0.11 & 0.91 \\
\hline $\begin{array}{l}\text { I would not mind spending money on honey as a } \\
\text { complementary or alternative medicine }\end{array}$ & $187(62.3)$ & $85(28.3)$ & $28(9.3)$ & $<0.01$ & 0.73 & 0.09 & $<0.01$ & $<0.01$ & 0.47 \\
\hline $\begin{array}{l}\text { Honey is easy to be used as a complementary or } \\
\text { alternative medicine }\end{array}$ & $240(80)$ & $53(17.7)$ & $7(2.3)$ & $<0.01^{*}$ & $0.44 *$ & $0.01 *$ & $<0.01$ & 0.16 & 0.81 \\
\hline Honey has no side effects & $217(72.3)$ & $69(23)$ & $14(4.7)$ & 0.02 & 0.36 & 0.78 & $<0.01$ & 0.07 & 0.53 \\
\hline
\end{tabular}




\section{DISCUSSION}

The current study presented the use of and the perceptions about honey as CAM among the general public in Selangor. The findings indicated that more than half of the respondents used honey in the past three months as CAM. The use of honey as dietary supplement for general well-being was noted in more than $70 \%$ of the users. The Malays were noted be significantly more likely to use honey as CAM in the past three months of the survey. The Malay respondents were also observed to be more favourable towards honey as CAM as significantly more Malay respondents strongly agreed and agreed with 7 out of 9 survey statements. The use of honey in the Malay traditional medicine is undeniably common and has been applied in this medical system for centuries. Moreover, honey is regarded as nutritious and healthy in Islam, which is the main religion for the Malays in Malaysia (Eteraf-Oskouei and Najafi, 2013). Therefore, the high usage of honey as CAM among the Malay respondents in the current study may have been influenced by their local culture and religion.

Although most indications for honey use by the users in the present study involved common ailments, $13.1 \%(22 / 168)$ of them used honey to treat asthma. The use of honey as CAM for asthma is in fact not uncommon (Savithramma et al., 2007; Alshagga et al., 2011; Orhan et al., 2003). In a cross-sectional survey carried out among adult asthmatic patients in a Malaysian general hospital, $61.1 \%(58 / 95)$ of the patients used CAM and honey was identified as one of the most common type of CAM used (Alshagga et al., 2011). Studies using honey to treat asthma have also been published (Rhman, 2007; Kamaruzaman et al., 2014). Despite yielding promising findings, these studies were confined to research on small animal and non-randomized human studies. Randomized clinical trials to verify the efficacy and safety of honey in asthma are still lacking. Hence, the fact that a small percentage of the respondents in the current study used honey as CAM to treat asthma has raised a cause for concern. Although honey use may be argued to be relatively safe, such practice may delay appropriate treatment and may put patients at risk of disease exacerbations. Therefore, the use of honey in treating asthma especially as an alternative medicine should not be recommended (Eteraf-Oskouei and Najafi, 2013).

In the present study, $57.1 \%(96 / 168)$ and $53 \%(89 / 168)$ of the honey users used the substance to treat coughs and sore throat, respectively. The potential usefulness of honey on its own or in combination with other ingredients for treating coughs (Paul et al., 2007; Raeessi et al., 2013; Cohen et al., 2012; Sulaiman et al., 2011) and sore throats (Sulaiman et al., 2011) has been reported in previous studies. Honey is in fact recommended in treatment guidelines to treat coughs (Morice et al., 2006; Fashner et al., 2012). Nonetheless, evidence of the effectiveness of the local honeys (e.g., Tualang, Kelulut, and Nenas) in treating coughs, sore throats and other common ailments are still limited. This paucity warrants further studies. In the present study, the majority of the honey users and non-users strongly agreed and agreed that there was sufficient evidence for the benefits of honey. Despite such belief, it should be noted that the majority of honey users utilized the Internet and advertisements as their sources of information about honey. As a matter of fact, the use of the Internet to seek information about CAM is common among the public (Hyodo et al., 2005; Diaz et al., 2002). Nevertheless, such information obtained from the Internet would not necessarily be reliable and valid, and it could be misleading (Hyodo et al., 2005). Furthermore, a previous study by Hassali et al. (2012b) found that many advertisements for CAM did not comply with the Medicine Advertisements Board (MAB) guidelines and the Malaysian Code of Advertising Practice. Therefore, patients planning to use or already using honey as CAM should be recommended to talk to their healthcare providers so that they can be informed about both the benefits and limitations of using honey in treating diseases.

The non-users of honey in the present study appeared to be skeptical towards honey in several instances. For examples, the non-users were noted to be less likely to strongly agree and agree that honey as CAM would be free from side effects, and that it could stimulate the body's natural therapeutic power. In addition, the non-users were also less likely to strongly agree and agree that they are willing recommend honey as CAM to others and to pay for honey as CAM. These skeptical attitudes and the unwillingness to pay for honey as CAM could be the reasons why honey was not a choice of treatment modality among the non-users. Interestingly, although not using honey as CAM in the past 3 months of the survey, the non-users also showed interest in using honey to treat common ailments than using the modern medicines.

In the present study, honey users in general held the belief that honey would have no side effects, probably due to the fact that honey is a natural product, and therefore is presumed safe. Nevertheless, although relatively harmless, the adverse effects from the consumption of honey have been reported (Paul et al., 2007; Özhan et al., 2004; Yocum and Khan, 1994). In a previous study in the U.S.A., the use of honey to suppress coughs produced a combination of mild reactions that included hyperactivity, nervousness, and insomnia (Paul et al., 2007). Other adverse effects relating to honey that have been reported include bradycardia and hypotension due to honey poisoning (Özhan et al., 2004; Jauhari et al., 2009), and allergy reactions (Yocum and Khan, 1994).

The present survey also showed that the majority of users obtained their honey supplies from the supermarkets and grocery stores. Previous studies on international market al.so indicated similar findings (Ványi et al., 2011; Batt and Liu, 2012). However, whether the honey obtained from the supermarkets and grocery stores would have similar quality and therapeutic effects to those reported in previous laboratory and clinical studies has remained questionable. The limitations of using table honeys obtained from the supermarket for treating wounds compared to the use of medical-grade honeys (MGH) have been reported in a British study (Cooper and Jenkins, 2009). The study found that honey obtained from the supermarkets in Britain showed low antibacterial activities compared to those of the MGH. Moreover, 
honey obtained from the supermarkets contained a wide range of potentially pathogenic microorganisms (Cooper and Jenkins, 2009), including Clostridium botulinum (Küplülü et al., 2006). Furthermore, the rise of counterfeit and adulterated honey that has become commonplace in the market in the recent years should provide a cause for concern (Yeow et al., 2013). Counterfeit and adulterated honey may not have the health benefits of pure honey and can be harmful.

Honey as a CAM has both strengths and limitations. Due to the local traditional medical systems that often incorporate honey as a treatment modality, the use of honey as CAM can be widespread. Healthcare providers especially doctors and pharmacists should therefore remain vigilant of the CAM modalities used by their patients (Miller et al., 2000). Moreover, they should be proactive in inquiring their patients about the use of CAM in an open and non-judgmental manner (Wahab et al., 2016). There should be a concern if patients rely solely on honey for treatment and avoid medical attention especially for treatment of serious diseases. In addition, members of the public who intend to use honey to treat diseases or maintain their health should be made aware of both its strengths and limitations. The present study has several limitations. In this study the respondents were recruited using convenience sampling method. Potentially those who agreed to participate in the study were generally interested in honey, even if they were not using it, thereby predisposing the results of this study to sampling bias. Because only three towns were selected, and that the selection of participants was made using convenience sampling method, the respondents were not representative of the local population; thus, the generalizability of the results of this study would be limited even at the regional level.

\section{CONCLUSION}

The majority of the respondents showed favourable perceptions about honey as CAM, and had either used the substance to treat diseases, or to promote health and general wellbeing. However, three issues have raised some concerns: the use of table honeys from unreliable sources and of questionable quality as CAM; the use of unreliable sources of information for honey use; and, the potential self-medication using honey for treating serious diseases. Future work should not only aim to produce more scientific evidences of the benefits and safety of honey, but also to enhance consumers' understanding about both the strengths and limitations of honey as CAM to prevent misconceptions.

\section{ACKNOWLEDGEMENT}

Financial support and sponsorship: This work was supported in part by the Universiti Teknologi MARA under the Lestari grant, 600-IRMI/DANA 5/3/LESTARI (0006/2016).

Conflict of Interests: There are no conflicts of interest.

\section{REFERENCES}

Abdulrhman M, El Hefnawy M, Ali R, Hamid IA, El-Goud AA, Refai D. Effects of honey, sucrose and glucose on blood glucose and C- peptide in patients with type 1 diabetes mellitus. Complementary therapies in clinical practice. 2013; 19:15-9.

Ajibola A. Novel Insights into the Health Importance of Natural Honey. Malaysian Journal of Medical Sciences. 2015; 22:7-22.

Alshagga MA, Al-Dubai SA, Faiq SSM, Yusuf AA. Use of complementary and alternative medicine among asthmatic patients in primary care clinics in Malaysia. Annals of thoracic medicine. 2011; $6: 115$.

Arvanitoyannis I, Krystallis A. An empirical examination of the determinants of honey consumption in Romania. International journal of food science \& technology. 2006; 41:1164-76.

Atwa A-DA, Abu Shahba RY, Mostafa M, Hashem MI. Effect of honey in preventing gingivitis and dental caries in patients undergoing orthodontic treatment. The Saudi dental journal. 2014; 26:108-14.

Bardy J, Slevin NJ, Mais KL, Molassiotis A. A systematic review of honey uses and its potential value within oncology care. Journal of Clinical Nursing. 2008; 17:2604-23.

Barnes PM, Bloom B, Nahin RL, Statistics NCfH. Complementary and alternative medicine use among adults and children: United States, 2007. US Department of Health and Human Services, Centers for Disease Control and Prevention, National Center for Health Statistics Hyattsville, MD; 2008.

Batt PJ, Liu A. Consumer behaviour towards honey products in Western Australia. British Food Journal. 2012; 114:285-97.

Bhatti I, Inayat S, Uzair B, Menaa F, Bakhsh S, Khan H, et al. Effects of Nigella sativa (Kalonji) and Honey on Lipid Profile of Hyper lipidemic Smokers.

Burge SK, Albright TL. Use of complementary and alternative medicine among family practice patients in south Texas. American Journal of Public Health. 2002; 92:1614-6.

Clarke TC, Black LI, Stussman BJ, Barnes PM, Nahin RL. Trends in the use of complementary health approaches among adults: United States, 2002-2012. National health statistics reports. 2015:1.

Cohen HA, Rozen J, Kristal H, Laks Y, Berkovitch M, Uziel Y, et al. Effect of honey on nocturnal cough and sleep quality: a double-blind, randomized, placebo-controlled study. Pediatrics. 2012; 130:465-71.

Cooper RA, Jenkins L. ORIGINAL RESEARCH-A Comparison Between Medical Grade Honey and Table Honeys in Relation to Antimicrobial Efficacy. Wounds. 2009; 21:29.

Diaz JA, Griffith RA, Ng JJ, Reinert SE, Friedmann PD, Moulton AW. Patients' use of the Internet for medical information. Journal of general internal medicine. 2002; 17:180-5.

Eteraf-Oskouei T, Najafi M. Traditional and modern uses of natural honey in human diseases: a review. Iranian journal of basic medical sciences. 2013; 16:731-42.

Fashner J, Ericson K, Werner S. Treatment of the common cold in children and adults. American family physician. 2012; 86: 153.

Hassali MA, Saleem F, Shafie AA, Al-Qazaz HK, Farooqui M, Aljadhey $\mathrm{H}$, et al. Assessment of general public perceptions toward traditional medicines used for aphrodisiac purpose in state of Penang, Malaysia. Complementary therapies in clinical practice. 2012a; 18:257-60.

Hassali MA, Saleem F, Aljadhey H, Khan TM. Evaluating the Content of Advertisements for Dietary Supplements in Malaysian Women's Magazines. Drug Information Journal. 2012b; 46:723-8.

Hussein SZ, MohdYusoff K, Makpol S, MohdYusof YA. Gelam Honey Inhibits the Production of Proinflammatory, Mediators NO, P G E 2, TNF- $\alpha$, and IL-6 in Carrageenan-Induced Acute Paw Edema in Rats. Evidence-Based Complementary and Alternative Medicine. 2012.

Hyodo I, Amano N, Eguchi K, Narabayashi M, Imanishi J, Hirai M, et al. Nationwide survey on complementary and alternative medicine in cancer patients in Japan. Journal of clinical oncology. 2005; 23:2645-54

Ismaiel S, Al Kahtani S, Adgaba N, Al-Ghamdi AA, Zulail A. Factors That Affect Consumption Patterns and Market Demands for Honey in the Kingdom of Saudi Arabia. Food and Nutrition Sciences. 2014; 5:1725.

Jauhari A, Johorey A, Banerjee I, Shrestha P, Singhal K. Nearly fatal wild honey intoxication: A case report of seven cases. Journal of Clinical and Diagnosis Research. 2009; 3:1685-9. 
Kamaruzaman NA, Sulaiman SA, Kaur G, Yahaya B. Inhalation of honey reduces airway inflammation and histopathological changes in a rabbit model of ovalbumin-induced chronic asthma. BMC complementary and alternative medicine. 2014; 14:1.

Kujawska M, Zamudio F, Hilgert NI. Honey-based mixtures used in home medicine by nonindigenous population of Misiones, Argentina. Evidence-Based Complementary and Alternative Medicine. $2012 ; 2012$

Küplülü Ö, Göncüoğlu M, Özdemir H, Koluman A. Incidence of Clostridium botulinum spores in honey in Turkey. Food Control. 2006; 17:222-4.

Lee MS, Lee MS, Lim HJ, Moon SR. Survey of the use of complementary and alternative medicine among Korean diabetes mellitus patients. Pharmacoepidemiology and Drug Safety. 2004; 13:167-71.

Miller LG, Hume A, Harris IM, Jackson EA, Kanmaz TJ, Cauffield JS, et al. White paper on herbal products. Pharmacotherapy: The Journal of Human Pharmacology and Drug Therapy. 2000; 20:877-87.

Mitha S, Nagarajan V, Babar MG, Siddiqui MJA, Jamshed SQ. Reasons of using complementary and alternative medicines (CAM) among elderly Malaysians of Kuala Lumpur and Selangor states: An exploratory study. Journal of Young Pharmacists. 2013; 5:50-3.

Morice A, McGarvey L, Pavord I. Recommendations for the management of cough in adults. Thorax. 2006; 61:i1-i24.

Orhan F, Sekerel BE, Kocabas CN, Sackesen C, Adalioglu G, Tuncer A. Complementary and alternative medicine in children with asthma. Annals of Allergy, Asthma \& Immunology. 2003; 90:611-5.

Özhan H, Akdemir R, Yazici M, Gündüz H, Duran S, Uyan C. Cardiac emergencies caused by honey ingestion: a single centre experience. Emergency medicine journal. 2004; 21:742-4.

Paul IM, Beiler J, McMonagle A, Shaffer ML, Duda L, Berlin CM. Effect of honey, dextromethorphan, and no treatment on nocturnal cough and sleep quality for coughing children and their parents. Archives of pediatrics \& adolescent medicine. 2007; 161:1140-6.

Pocol CB, Bolboacă SD. Perceptions and trends related to the consumption of honey: A case study of North-West Romania. International Journal of Consumer Studies. 2013; 37:642-9.

Raeessi MA, Aslani J, Raeessi N, Gharaie H, Zarchi AAK, Raeessi F. Honey plus coffee versus systemic steroid in the treatment of persistent post-infectious cough: a randomised controlled trial. Primary Care Respiratory Journal. 2013; 22:325-30.

Rhman MAMMA. Bee Honey Nebulization as a Non Traditional Treatment of Acute Bronchial Asthma in Infants and Children. Malaysian Journal of Medical Sciences. 2007; 14.

Salehi A, Jabarzare S, Neurmohamadi M, Kheiri S, RafieianKopaei M. A double blind clinical trial on the efficacy of honey drop in vernal keratoconjunctivitis. Evidence-Based Complementary and Alternative Medicine. 2014; 2014.
Savithramma N, Sulochana C, Rao K. Ethnobotanical survey of plants used to treat asthma in Andhra Pradesh, India. Journal of Ethnopharmacology. 2007; 113:54-61.

Siti Z, Tahir A, Farah AI, Fazlin SA, Sondi S, Azman A, et al. Use of traditional and complementary medicine in Malaysia: a baseline study. Complementary therapies in medicine. 2009; 17:292-9.

Sulaiman SA, Hasan H, Deris ZZ, Wahab M, Yusof RC, Naing $\mathrm{NN}$, et al. The benefit of Tualang honey in reducing acute respiratory symptoms among Malaysian hajj pilgrims: a preliminary study. J Api Pro Api Medic Sci. 2011; 3:38-44.

Ványi GÁ, Csapó Z, Kárpáti L. Evaluation of consumers' honey purchase habits in Hungary. Journal of Food Products Marketing. 2011; 17:227-40.

Ventola CL. Current issues regarding complementary and alternative medicine (CAM) in the United States: Part 1: the widespread use of CAM and the need for better-informed health care professionals to provide patient counseling. Pharmacy and Therapeutics. 2010; 35:461.

Wahab MS, Sakthong P, Winit-Watjana W. Pharmacy students' attitudes and perceptions about complementary and alternative medicine: a systematic review. Thai Journal of Pharmaceutical Sciences. 2016; 40 (2): 102-114.

Wahab MSA, Ali AA, Zulkifly HH, Aziz NA. The need for evidence-based complementary and alternative medicine (CAM) information in Malaysian pharmacy curricula based on pharmacy students' attitudes and perceptions towards CAM. Currents in Pharmacy Teaching and Learning. 2014; 6:114-21.

Yeow SHC, Chin STS, Yeow JA, Tan KS. Consumer Purchase Intentions and Honey Related Products. Journal of Marketing Research \& Case Studies. 2013; 2013:1.

Yocum MW, Khan DA, editors. Assessment of patients who have experienced anaphylaxis: a 3 -year survey. Mayo Clinic Proceedings; 1994.

\section{How to cite this article:}

Wahab MSA, Othman N, Othman NHI, Jamari AA, Ali AA. Exploring the use of and perceptions about honey as complementary and alternative medicine among the general public in the state of Selangor, Malaysia. J App Pharm Sci, 2017; 7 (12): 144-150. 